\title{
Effect of socioeconomic status on survival from cervical cancer in Sheffield
}

\author{
P C MILNER AND M WATTS \\ From the Department of Community Medicine, Sheffield Health Authority, Westbrook House, Sharrow Vale \\ Road, Sheffield S11 $8 E U$
}

SUMMARY The relation between age at registration, socioeconomic status, and survival from cervical cance for women resident in Sheffield was examined using the 556 such cases registered with the Trent Cancer Registry from 1971 to 1984 . The address and electoral ward at registration were used to categorise the socioeconomic status of $99 \%$ of the women. Five year survival for all cases was $49 \%$, increasing age having a predictable deleterious effect. Socioeconomic status seemed to have little effect on survival, especially when the covarying effect of age had been taken into account. It is hypothesised that the survival inequalities for cervical cancer demonstrated elsewhere have largely been prevented in Sheffield by good access to effective treatment from the National Health Service.

A recent study of cervical cancer in Sheffield residents showed that the case fatality rate, defined as the ratio of the number of deaths to the number of cases registered in a given time period, was significantly higher in electoral wards with the highest proportion of unskilled and semiskilled workers. ${ }^{1}$ Shorter survival of women with low socioeconomic status suffering from cervical cancer has been described in urban blacks in Soweto, South Africa ${ }^{2}$ and, less convincingly, in the deprived populations of South Australia. ${ }^{3}$ In this country, five year age-standardised survival rates for cervical cancer showed a $25 \%$ difference between the region with the highest (Oxford-58\%) compared to that with the lowest (Yorkshire-47\%), for cases registered from 1971 to $1973 .{ }^{4}$ The use of place of residence as a marker of socioeconomic status in Sheffield has been of value in a recent study in which predictable and marked differentials in disease experience and health care utilisation were demonstrated. ${ }^{5}$ The use of area of residence to classify socioeconomic status instead of occupation has been commended in the most recent occupational mortality decennial supplement. ${ }^{6}$ However, the relation between socioeconomic status and cervical cancer survival, investigated on a small area basis, has not been reported before in this country. Such small area analysis can highlight large differences not apparent at a regional level, and its use is demonstrated here.

\section{Methods}

The survival details, age, occupation, and address of the 564 Sheffield residents registered with the Trent Cancer Registry with cervical cancer (ICD code: 180) from 1971 to 1984 were extracted. Eight cases from the earlier years were duplicates, leaving 556 to be studied. The electoral ward of residence was obtained from the address at registration using the electoral register. Only $30 \%$ of cases had sufficient information recorded for the occupational social class to be ascertained. An alternative approach using area of residence to derive another measure of social class allowed $99 \%$ of cases to be classified, thus permitting 548 cases to be studied. The 29 Sheffield electoral wards were ranked in ascending order according to the percentage of semiskilled and unskilled workers in the 1981 census small area statistics (range 7-41\%). They were then divided into quintiles of $6,6,5,6$, and 6 wards to collect together areas of approximately equivalent socioeconomic status and similar numbers of women. The survival time was defined as the time from the anniversary date (the earliest of the first outpatient appointment date, the first treatment date or the first hospital admission date) to either the date of death or 30 June 1986, the last day on which current survival information was known. Seventeen cases were registered after death and thus had no anniversary date. The survival procedure in the SAS computerised 
statistical package was used to explore the relation between age at registration, socioeconomic status, and survival.

\section{Results}

The numbers of cases and deaths, together with an estimate from the 1981 census of the number of women at risk, are shown in table 1 for each of the five socioeconomic categories. The 25th, 50th, and 75th percentiles of age at registration for all the cases are 47,
58 , and 68 years and are also shown in table 1 . There is some variation in the frequency distributions of age at registration between socioeconomic categories, but this is not statistically significant $\left(\chi^{2}=18 \cdot 0\right.$, degrees of freedom $=12, \mathrm{p}=0 \cdot 12$ ).

Five year survival for all cases was 49\%. Age had a predictable effect on survival. ${ }^{7}$ Younger women (under 48 years) had markedly better survival, and older women (over 68 years) markedly worse survival, than women in the middle of the age range (fig $1: \log$ rank test; $\chi^{2}=83$, degrees of freedom $=3, p<0.0001$ ).

Table 1 Age at registration frequency distribution of the socioeconomic categories

\begin{tabular}{|c|c|c|c|c|c|c|c|c|c|}
\hline \multirow{2}{*}{$\begin{array}{l}\text { Socioeconomic } \\
\text { category }\end{array}$} & \multirow{2}{*}{\multicolumn{2}{|c|}{$\begin{array}{l}\text { No }(\%) \text { of women } \\
\geqslant 15 \text { in } 1981\end{array}$}} & \multirow{2}{*}{\multicolumn{2}{|c|}{$\begin{array}{l}\text { No (\%) of cases } \\
1971-84\end{array}$}} & \multicolumn{5}{|c|}{ No. of cases (deaths) by age range } \\
\hline & & & & & \multicolumn{2}{|c|}{$\leqslant 47 y r$} & $48-58 \mathrm{yr}$ & $59-68 \mathrm{yr}$ & $\geqslant 69 \mathrm{yr}$ \\
\hline $\begin{array}{c}1 \\
2 \\
3 \\
4 \\
5 \\
\text { Total }\end{array}$ & $\begin{array}{r}46127 \\
47315 \\
41481 \\
42660 \\
44776 \\
222359\end{array}$ & $\begin{array}{l}(21) \\
(21) \\
(19) \\
(19) \\
(20) \\
(100)\end{array}$ & \begin{tabular}{r|}
78 \\
82 \\
82 \\
115 \\
191 \\
548
\end{tabular} & 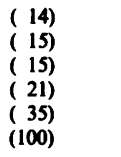 & $\begin{array}{r}19 \\
24 \\
24 \\
28 \\
41 \\
136\end{array}$ & $\begin{array}{l}(4) \\
(4) \\
(5) \\
(4) \\
(12) \\
(29)\end{array}$ & $\begin{aligned} 16 & (8) \\
13 & (6) \\
15 & (7) \\
40 & (18) \\
54 & (35) \\
138 & (74)\end{aligned}$ & $\begin{aligned} 21 & (13) \\
18 & (9) \\
21 & (11) \\
27 & (15) \\
51 & (31) \\
138 & (79)\end{aligned}$ & $\begin{aligned} 22 & (17) \\
27 & (19) \\
22 & (17) \\
20 & (12) \\
45 & (35) \\
136 & (100)\end{aligned}$ \\
\hline
\end{tabular}

$\chi^{2}=18.0$ for a difference in age at registration between the categories Degrees of freedom $=12$ $\mathrm{p}=0.12$

Women in category 5 reside in areas with the highest proportions of semiskilled and unskilled workers.

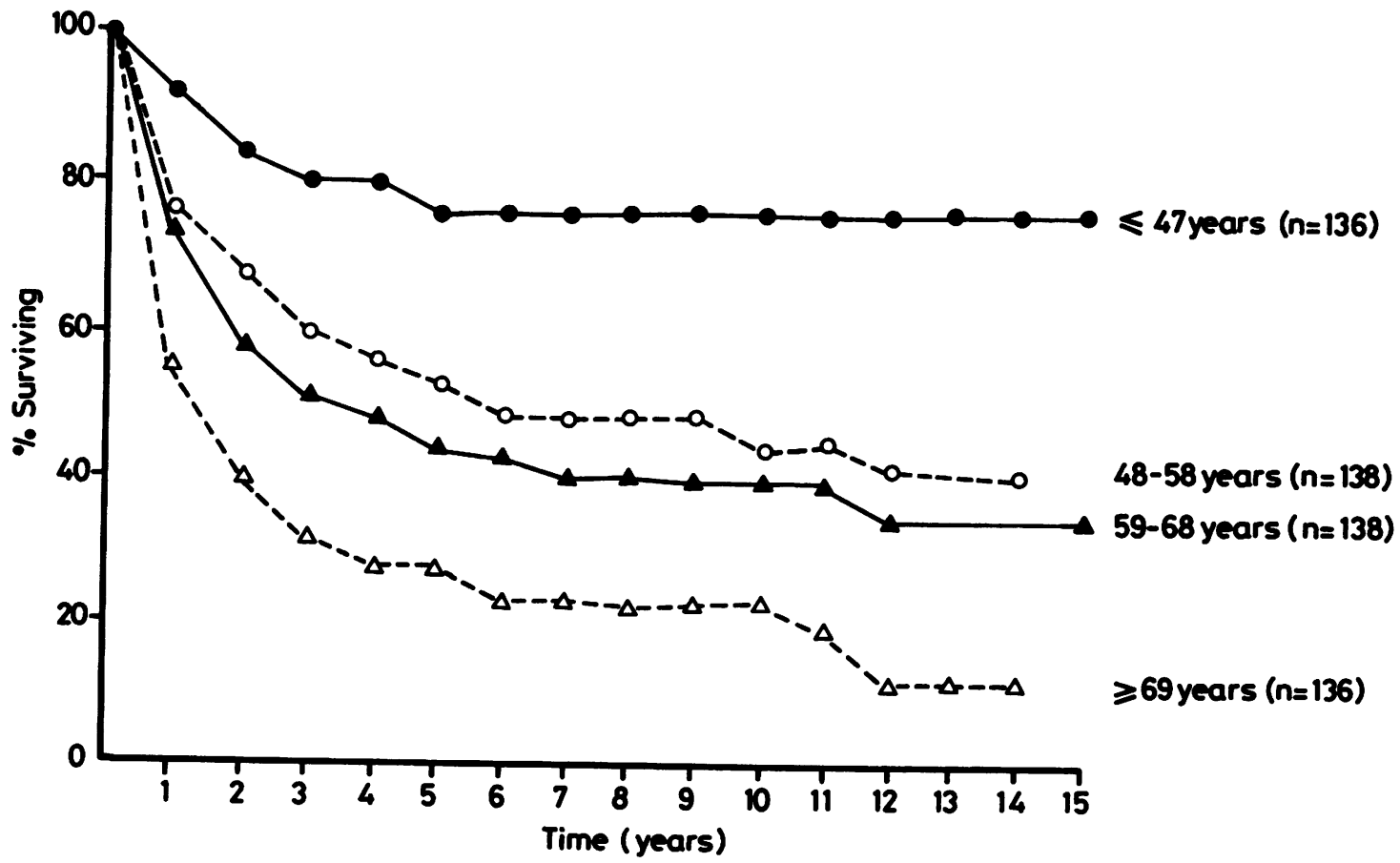

Fig 1 Survival curves for the four age groupings of 47 years and under, 48-58 years, 59-68 years, and 69 years and over (log rank test; $\chi^{2}=83$, degrees of freedom $=3, p<0.0001$ ). 
The survival curves for the five socioeconomic categories are shown in figure 2. The log rank test of the hypothesis that women in these categories experience different survival rates just failed to reach statistical significance at the $5 \%$ level (table $2 ; \chi^{2}=9 \cdot 0$, degrees of freedom $=4, p=0.06$ ).

However, socioeconomic categories containing women with the youngest age distribution tended to have the best survival. Thus, when the estimated hazard functions for the four age groupings of 48 years or under, 49-58 years, 59-68 years, and 69 years or over were used to recalculate the expected numbers of deaths in each socioeconomic category according to the age distribution in that category, the differences between the observed and expected numbers of deaths were reduced (table 2) and these were not significant (log rank test; $\chi^{2}=7 \cdot 4$, degrees of freedom $=4$, $\mathrm{p}=0 \cdot 13$ ).

\section{Discussion}

Our findings do not support the hypothesis that there is a marked effect of socioeconomic factors on survival from cervical cancer in Sheffield. Any differences in survival between the groups which could be attributable to the net effect of differing stage at presentation, aggressiveness of disease, and/or response to treatment were not great enough to be detected once the analysis had allowed for the effect of age. Good access to and effective treatment from the National Health Service in Sheffield may have largely prevented the survival inequalities for cervical cancer

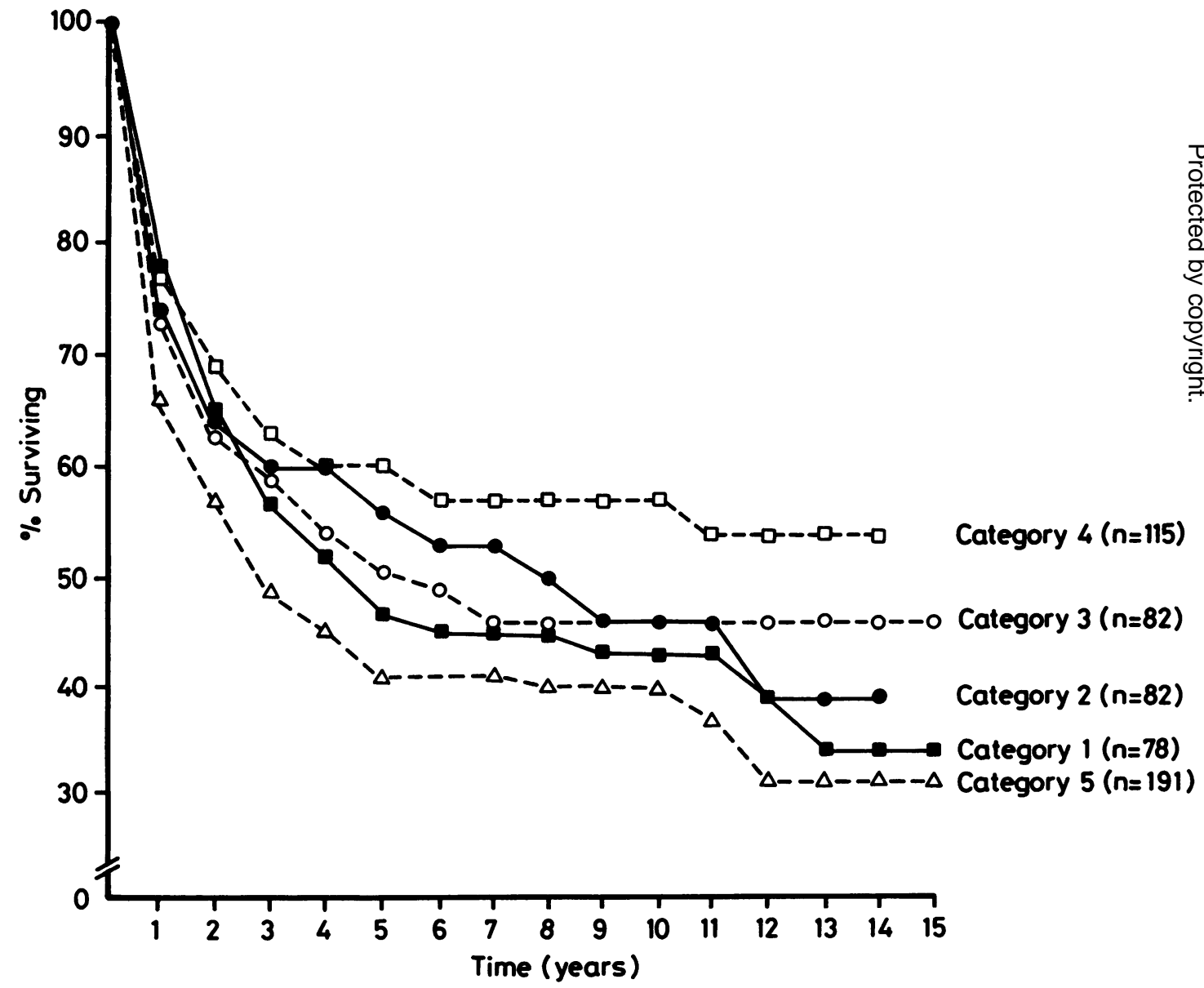

Fig 2 Survival curves for the five socioeconomic categories (log rank test; $\chi^{2}=9 \cdot 0$, degrees of freedom=4, $p=0 \cdot 06$ ). Socioeconomic status was derived from place of residence, and women in category 5 reside in areas with the highest proportion of semiskilled and unskilled workers. 
Table 2 Observed and expected deaths for the socioeconomic categories used in the log rank test showing the effect of allowing for differences in age distributions of the categories

\begin{tabular}{|c|c|c|c|c|c|}
\hline $\begin{array}{l}\text { Socioeconomic } \\
\text { categories }\end{array}$ & $\begin{array}{l}\text { Observed } \\
\text { deaths }\end{array}$ & $\begin{array}{l}\text { Expected } \\
\text { deaths }\end{array}$ & Difference & $\begin{array}{l}\text { Age adjusted } \\
\text { expected deaths }\end{array}$ & $\begin{array}{l}\text { Age adjusted } \\
\text { difference }\end{array}$ \\
\hline $\begin{array}{c}1 \\
2 \\
3 \\
4 \\
5 \\
\text { Total }\end{array}$ & $\begin{array}{r}42 \\
38 \\
40 \\
49 \\
113 \\
282\end{array}$ & $\begin{array}{r}42.3 \\
42.1 \\
41.8 \\
64.1 \\
91.7 \\
282.0\end{array}$ & $\begin{array}{r}-0.3 \\
-4.1 \\
-1.8 \\
-15.1 \\
+21.3 \\
0\end{array}$ & $\begin{array}{r}43 \cdot 6 \\
43 \cdot 0 \\
40.8 \\
61 \cdot 4 \\
93 \cdot 2 \\
282.0\end{array}$ & $\begin{array}{r}-1.6 \\
-5.0 \\
-0.8 \\
-12.4 \\
+19.8 \\
0\end{array}$ \\
\hline $\begin{array}{l}\chi^{2}=9.0 \\
\text { degrees of freed } \\
p=0.06\end{array}$ & & & & \multicolumn{2}{|c|}{$\begin{array}{l}\text { Age adjusted } \chi^{2}=7.4 \\
\text { degrees of freedom }=4 \\
p=0.13\end{array}$} \\
\hline
\end{tabular}

demonstrated elsewhere. This conclusion concurs with the independent work on geographical variation in mortality from conditions amenable to treatment. ${ }^{8}$ This study ranked the Sheffield Health Authority area in the top sixth of a national distribution of districts for achieving good results against cervical cancer, after standardising for age and adverse social factors.

We are grateful for the help of the Trent Cancer Registry Scheme, Dr J N Todd, District Medical Officer, Sheffield, and the University of Sheffield computing facilities.

Address for correspondence: Dr P C Milner, Lecturer in Community Medicine, Department of Community Medicine, University of Sheffield Medical School, Beech Hill Road, Sheffield S10 2RX

\section{References}

${ }^{1}$ Johnson IS, Milner PC, Todd JN. An assessment of cervical cytology screening in Sheffield. Community Med in press.

2 Walker ARP, Walker BF, Siwedi D, et al. Low survival of South African urban black women with cervical cancer. Br J Obstet Gynaecol 1985; 92: 1272-8.

${ }^{3}$ Bonett A, Roder D, Esterman A. Determinants of case survival for cancers of the lung, colon, breast and cervix in South Australia. Med J Aust 1984; 141: 705-9.

${ }^{4}$ Silman AJ, Evans SJW. Regional differences in survival from cancer. Community Med 1981; 3: 291-7.

5 Johnson IS, Coyne AM, Milner PC, et al. Health care and disease a profile of Sheffield. Sheffield: Sheffield Health Authority, 1986.

${ }^{6}$ Office of Population Censuses and Surveys. Occupational mortality decennial supplement 1979-80, 1982-83 Great Britain: Part I Commentary. London: Her Majesty's Stationery Office, 1986.

${ }^{7}$ Cancer Research Campaign. Trends in cancer survival in Great Britain. London: Cancer research campaign, 1982.

${ }^{8}$ Charlton JRH, Hartley RM, Silver R, Holland WW. Geographical variation in mortality from conditions amenable to medical intervention in England and Wales. Lancet 1983; i: 691-6. 